University of Nebraska - Lincoln

DigitalCommons@University of Nebraska - Lincoln

To Improve the Academy

Professional and Organizational Development Network in Higher Education

1995

A Quantum Leap in Faculty Development: Beyond Reflective Practice

Donna Qualters

Follow this and additional works at: https://digitalcommons.unl.edu/podimproveacad

Part of the Higher Education Administration Commons

Qualters, Donna, "A Quantum Leap in Faculty Development: Beyond Reflective Practice" (1995). To Improve the Academy. 341.

https://digitalcommons.unl.edu/podimproveacad/341

This Article is brought to you for free and open access by the Professional and Organizational Development Network in Higher Education at DigitalCommons@University of Nebraska - Lincoln. It has been accepted for inclusion in To Improve the Academy by an authorized administrator of DigitalCommons@University of Nebraska - Lincoln. 


\section{A Quantum Leap in Faculty Development: Beyond Reflective Practice}

\section{Donna Qualters}

University of Massachusetts Medical Center

Quantum theory has introduced a new perspective of looking at reality. This article reviews current theories of reflective practice, discussion, and transformative learning as they apply to faculty development and explores dialogue and quantum theory as the next step in faculty transformation.

Loneliness invaded not only our science, but whole cultures. In America, we raised individualism to its highest expression, each of us protecting our boundaries, asserting our rights, creating a culture that Bellah et al. writes leaves the individual suspended in glorious, but terrifying, isolation.

These words by Margaret Wheatley preface her book on leadership and quantum theory $(1993$, p. 30$)$. They refer to a culture that is strongly exemplified by the teaching world of academia. As faculty members, we protect our boundaries (the classroom), assert our rights (to conduct teaching in private), and leave ourselves in terrifying isolation. Lee Shulman addressed this same issue when he discussed the isolation faculty experience in the classroom (Shulman, 1993). Both authors address an issue at the very heart of faculty development. How can we develop as teachers if we remain in isolation? If teaching is done behind closed doors, how can faculty enrich their teaching and their academic experience? Both Wheatley and Shulman would say 
they can't. If we accept Wheatley's premise that we live in a quantum world, if "things" have disappeared, if "in a quantum world, relationships are not just interesting...they are all there is to reality" $(1993, \mathrm{pg}$. 32), then faculty development must move beyond its traditional, linear approach. In the words of Karl Weick "we must stop arguing about truth and get on with figuring what works best" (Weick cited in Wheatley, 1993, pg. 37).

Leaders in a quantum world also have a different role. Using a jazz metaphor, Wheatly suggests that the traditional functions of making decisions and setting examples must be replaced.

As leaders we play a crucial role in selecting melody, setting the tempo, establishing the key, and inviting the players. But that is all we do. The music comes from something we cannot direct, from a unified whole created among the players...in the end, then it works, we sit back, amazed and grateful (Wheatley, 1993, p. 44)

In a more direct connection to academic teaching, Parker Palmer echoes Wheatly's conceptual framework and suggests the creation of a community of discourse about teaching and learning (Palmer, 1993). He asks us to get over our habit of reducing teaching to "how to do it" questions, much as Wheatley asks us to get over our Newtonian quest for predictability, to stop analyzing the parts to arrive at the whole. Instead we need to look at "the challenge of ideas, the exploration of shared practice, the uniqueness of each teacher's genius, the mystery at the heart of the educational exchange" (Palmer, 1993, p. 10). Wheatley poses her challenge a little differently, but still advocates the same concept. "We need to see beyond the many fragments to the whole, we need to step back far enough to appreciate how things move and change as a coherent whole" (Wheatley, 1993).

Palmer, like Wheatley, also envisions leadership in a new way. Leaders need to invite conversations to create the learning community. The most powerful leadership is the type that provides the ways and means to do things people want to do but feel unable to do for themselves. This type of leadership will tap energies much more effectively than the exercise of power or coercion (Palmer, 1993). The role of the leader is to bring the people together and then watch and see what their energy creates. 
If we accept this principle as a new paradigm, what does it mean for faculty development? New ideas are being tried and tested, some as deceptively simple as "personalization" (Katz \& Henry, 1988) others conceptually more complicated, such as "reflective practice" (Schön, 1983). Faculty development, as traditionally conceived, is relatively narrow, and this new view certainly implies a movement beyond the traditional workshops, individual consultations, teaching tips, and the like. But what will replace the old paradigm? I suggest that we should explore the use of reflective practice, critical thinking, discussion, transformative learning, and dialogue as a basis for designing a new approach to faculty development.

\section{Reflective Practice}

Schon coined the term "knowing-in-action" to describe the way skillful practitioners often possess knowledge that they cannot name or identify (Schön, 1983, pg. 50). "Knowing in action" is defined by three salient characteristics (Schön, 1983, p. 54):

1. Actions, recognitions, and judgments that we do not think about but carry on in a spontaneous manner.

2. An unawareness of having learned these things, we just do them.

3. In some cases, awareness of the internalized understanding; in other cases unaware, yet in both cases an inability to describe the knowing.

In essence, "skillful action often reveals a knowing more than we can say" (p. 51). Shulman uses this concept again when referring to teachers as practitioners who know more than they ever try to articulate (Shulman, 1987). I found this to be true when working with faculty members who were trained in health professions. As we worked together to help them transfer their skills into a classroom setting, they were struck over and over by the fact that they "knew" a great deal of educational theory, they just never identified it as such. For example, in a session on Classroom Assessment based on the work of Angelo and Cross, they discovered that the idea was very similar to clinical assessment of patients they had practiced for years. (Qualters, 1995) 
The principles and practices were very similar: find out what is wrong with the patient/student; prescribe a course of action; assess to see if the patient is healing or the student is learning; adjust the course of action based on assessment. By reflecting on their practice they were able to transfer this skill to the classroom. These techniques simply needed to be "named" for them. They certainly knew more than they could say. Schön identified this transformation as a shift from knowing-in-action to knowledge-in-action, an awareness that one possesses knowledge that is rigorous and relevant (1983, p. 59).

But knowledge-in-action is not enough. Practitioners need to have a mechanism to identify, evaluate, adjust and apply this knowledge to make it useful. Schon calls this concept "reflective practice". Schön feels that through reflection, practitioners can bring to awareness and evaluate the tacit understanding that is part of their experience in their specialized practice. As a result, they will be able to make sense of new and unique situations when they arise (Schön, 1983).

Of course, many of us do reflect on practice. Teachers often leave class wondering what went wrong, or why a certain situation occurred, and what can they do to change it. But this kind of instantaneous, on-the-spot reflection is less intensive than that which Schön believes is necessary when he suggests "reflection-in-action." "Reflection-inaction" is not time-constrained; it can be instantaneous or it can last over a period of months. It can be a reflection on the immediate event or a reflection on the tacit norms and assumptions that underlie our actions (Schön, 1983). This kind of "double loop learning" focuses on understanding not only what we do but why we do it (Argyris \& Schön cited in Issacs, 1993).

The Allied Health faculty members I worked with provide a good example of "double loop learning" in conjunction with reflective practice. In a discussion on how to handle difficult students in class, we talked not only about how they handled difficult patients in the clinic but why they dealt with them in a specific way. We explored the "theory" behind their behavior. We then discussed whether this was appropriate for the classroom (it was), and why it would be a good strategy for dealing with difficult students.

This idea is also in concert with quantum theory principles: Wheatley asserts that the environment remains uncreated until we 
interact with it and that there is no describing it until we engage it (Wheatley, 1993). So when we take knowledge and transfer it to a new situation, its efficacy can only be determined in action. This principle, reflective practice followed by action, holds a promise for for changing the field of faculty development. The American Association of Higher Education devoted an entire conference to this topic in the summer of 1995, and the conference itself may be a means for "improving teaching through conversation and community" (Palmer, 1993, pg. 8).

\section{Discussion}

As Parker Palmer points out, faculty members belong to one of the few professions that do not engage in conversation with colleagues (1993). He refers to this as the "privatization of teaching." Its roots, he speculates, are in the concept and practice of academic freedom, but it flourishes because faculty members often choose it as a way to protect themselves from evaluation. However, this development has had dangerous consequences for higher education: "The most likely outcome when any function is privatized is that people will perform the function conservatively, refusing to stray far from the silent consensus on what "works," even when it clearly does not" (Palmer, 1993, p. 8). I once talked to a faculty member who said he had taught the same way for twenty years, even though he felt for the last ten that his method hadn't worked. Incredibly, each year he applied for a waiver from student evaluations, based on his many years of teaching experience.

Palmer's suggestion to engage in continuing, thoughtful conversation that goes beyond the techniques of teaching promises to help eliminate the isolation that teachers experience in higher education. I still remember the eager phone call from a faculty member in the semester following a teaching project. She called, elated, to tell me about an innovation she had tried in the classroom that morning that had wonderful, exciting results. A couple of days later she dropped by my office to tell me how good it was just to have someone to talk to about teaching issues and how this motivated her to continue to try new and different ways, but more importantly, to continue to reflect 
and question her practices and assumptions. This incident seems to exemplify Palmer's "community of discourse fed by the richness of our corporate experience" (Palmer, 1993, pg. 10).

Palmer advocates four techniques to stimulate this kind of creative conversation. The first technique is based on critical moments in teaching, which he defines as moments when "a learning opportunity will either open up or shut down for your students - depending, in part, on how you respond" (Palmer, 1993, pg. 10). An important aspect of a discussion of "critical moments" is that there are no "correct" answers. Instead, reflecting on practice with colleagues allows one to understand these situations in more meaningful ways and therefore makes practice stronger (Palmer, 1993). Brookfield, in his work on fostering critical thinking in adults, suggests a similar process he calls "critical incident exercises" (Brookfield, 1987). These exercises are used to help individuals identify incidents that have particular significance for them. Brookfield refers to the reflections done during these sessions as "identifying theories in use," which is composed of:

- contextually grounded ideas about what works best in that context

- explanation as to why these ideas work

- readiness to alter practice according to a changing context

The similarities between Schön's reflection-in-action and Brookfield's theories-in-use are obvious, a fact which Brookfield himself acknowledges (p. 155).

The second technique Palmer espouses for good conversation centers on the "human condition" of teachers and learners, by which he means metacognitive state of knowing ourselves in order to help us understand our students. It is only by confronting our own knowledge of ourselves and our fears that we can understand that of our students. Yet "we cannot see the fears that haunt our students because we ourselves are haunted by the fear that our students have rejected us" (Palmer, 1993, pg. 11). I once had a teacher ask me, "what are you 
most loathe to know about your work?" While the question made me extremely uncomfortable, it was only by discussing it that I was able to deal with that fear and put it in perspective.

Palmer's third technique for improving teaching though conversation is to discuss the metaphors and images of what we are doing when we teach. His own example of his early image of teaching "like a sheepdog" revealed that he viewed teaching as keeping everyone in line, in the right pasture, like sheep. This allowed him to explore why he thought that way and if it was true.

His last technique is autobiographical reflection on the origins of our teaching vocations and on the great teachers in our lives. Since the "great teachers" will have used very different (in some cases, mutually exclusive) techniques, the purpose is not to examine their methods. Palmer believes that, through conversations, we can identify their commonalties: a high degree of self-knowledge, trust in their own nature, and a willingness to teach directly from that self knowledge (Palmer, 1993).

\section{Transformative Learning}

Mezirow's theory of transformative learning also bears a similarity to double loop learning. Mezirow defines transformative learning as critical self-reflection in which learners become aware of their assumptions, reflect on them, and then question whether or not they are valid (Mezirow, 1991). Many times this process will lead one to the realization that the assumptions may not be valid and thereby lead to re-forming or transformation of those assumptions, which in turn leads to new ways of interpreting reality. Again, reflection is a key component of this theory and in many ways resembles Schon's reflective practice.

Patricia Cranton has done interesting work on applying Mezirow's theory to faculty development (Cranton, 1994). She argues that while many faculty development activities appear voluntary, in the reality of higher education culture they are really mandatory. Faculty must give evidence of having examined their teaching and also demonstrate improvement thereof. Traditional faculty development activi- 
ties such as workshops, conferences, or additional coursework are designed for forming rather than transforming practice.

In order to introduce the transformative element into faculty development she suggest two approaches: engaging faculty in action research on their teaching; and the development of faculty group support programs, long-term mentors, or on-going peer consultations. These methods allow faculty to examine the assumptions that underlie their teaching practice.

\section{Dialogue}

The techniques discussed above share many characteristics, and whether we refer to reflective practice, double loop learning, critical incidents, support groups or just good conversation, they all seem to point in the same direction. But there is another set of ideas that goes beyond those described so far. We often hear the phrase "enter into a dialogue," and until recently that has usually meant enter into a discussion, which often leads to dialectics, which then leads to debate and a resolution that is usually accomplished by beating down the opposition (Schein, 1993). Recent work at MIT's Dialogue Project has developed a new meaning and use for dialogue that separates it from "discussion" and appears to have potential for faculty development.

Dialogue is the creative space in which entirely new ways of thinking and acting will emerge. Dialogue is a space of deep thinking, where there is nothing to prove, where well worn ways of thinking and being can be let go of. In a dialogue there is nothing to be solved and nothing to be defended (Isaacs, 1992, p. 1).

Dialogue can take the reflective learning process one crucial step further. Not only does it point out underlying assumptions but it helps one learn about the reasons that led one to adopt those assumptions. It is a metacognitive approach in which one learns about one's learning. Isaacs refers to it as "triple loop learning" and distinguishes it from double loop, which he feels encourages learning only to increase effectiveness rather than develop deeper self-knowledge. "Triple-loop learning is the learning that opens inquiry into underlying why's. It is the learning that permits insight into the nature of paradigm itself, not merely an assessment of which paradigm is superior" (Issacs, 1993, 
p.30). Dialogue helps us get to factors buried at such deep levels that we are not even aware of their influence on our feeling and attitudes. This process is called "proprioception" by Bohm, Factor and Garrett (1993), which they define as paying attention to why we are thinking the way we are thinking. Although we may believe that our attitude toward someone is based on their actions alone, it is more often shaped by underlying attitudes that are not related to that person at all. When we use the phrase "You're just like your mother, father, etc.," we are judging someone on feelings and assumptions associated with another individual. In a recent faculty dialogue meeting, someone referred to students as "adults," a remark that led the group to examine if that assumption was operating in our methodolgy and pedagogy. Although we never reached agreement on whether or not students are adults, many faculty members admitted that they did believe this assumption and were operating on that belief. Others realized that while they did not operate under that assumption, they felt a tension between their belief that students should be adults and the reality of the classroom that seemed to prove otherwise.

Dialogue helps us identify this phenomenon while it is occurring. Although dialogue is not aimed at changing behaviors or even moving participants toward a pre-determined goal, "nevertheless changes do occur because observed thought behaves differently from unobserved thought" (Bohm, et al., 1993, p. 6). Observed thought allows us to see thinking as something to be aware of as it is occurring, not something to reflect on after the fact. Dialogue may also allow the creation of collective thought. At one dialogue group a participant remarked that as faculty members we all wear masks. After lengthy reflections on what that statement might mean to us the topic was changed. However, at the next meeting it was raised again and some members revealed that they had been thinking about that concept between sessions and that it had had an effect on their teaching that week.

Dialogue can be a way to break down what Argyris calls "defensive routines," early conversational patterns which teach us to be polite and to avoid confrontations but which often lead to miscommunication (cited in Schein, 1993). Dialogue techniques create mutual trust and build common ground so that communication can be more valid and 
genuine, and dialogue appears to be a crucial link to opening the classroom door.

Schein asserts that discussion is a valid problem solving and decision making process only if we assume people share common meaning and understanding (Schein, 1993). However, I have found that faculty members often do not even share a common conception of the fundamental concept of teaching. To one it is the transfer of knowledge, to another it is facilitating learning, to yet another it is providing skill and tools to obtain knowledge, and so on. Of course this diversity may reflect more than simple definitional differences, since research has shown that teaching ability may be developmental (Sherman et al., 1987) and these differences could represent the developmental level of different teachers. However, it is difficult to discuss "our teaching" when we don't even share the same meaning for the terms. Dialogue can therefore make important contributions to faculty development, helping teachers create a common set of understandings in an atmosphere of trust. On our campus, a dialogue group this semester agreed to make the time commitment to visit each other's classrooms and then to sit and talk about what they had experienced. Not only was the commitment significant, but it marked the first time in recent memory that such a critical mass of peer reviews voluntarily took place in one semester.

The dialogue technique must be adopted cautiously, for as Bohm, Factor and Garrett point out, in the early stages dialogue will often lead to frustration (1992). In pursuing an activity that appears to have no goal or direction, participants often feel frustrated or angry and some may try to "take control," thereby polarizing the dialogue. It is important to create a "container" environment "in which people can allow a free flow of meaning and vigorous exploration of the collective background of their thought, their personal predispositions, the nature of their shared attention and the rigid features of their individual and collective assumptions" (Isaacs, 1992, p. 25). Schein has found that this container environment allows people to deal with issues that generate strong emotions and feelings without becoming polarized (Schein, 1993).

A skilled facilitator is important to the dialogue process. It is the facilitator's task to sustain dialogue through the initial stage (which 
may appear to be unstructured and non-directional) until the process can peel away the initial layers of resistance and create common understanding. Thus, skilled facilitators must model the suspension of their own categories and judgments for the participants in the dialogue (Schein, 1993). This suspension is especially important in the culture of higher education where members are judged on their ability to view ideas critically and to defend a particular intellectual position.

The dialogue technique has also been found to work best in groups numbering between twenty and forty (Bohm et al., 1993). Groups composed of less than twenty often do not have the diversity necessary to reveal underlying assumptions and sub-culture thinking, and groups of over forty are unwieldy and give participants fewer opportunities to speak. This requirement poses a serious problem for the use of dialogue in faculty development, since it can be extremely difficult to assemble and maintain a group of over twenty faculty over a sustained period, but it should not be a reason to reject the technique. Ways may be found to allow the dialogue technique to operate effectively in groups of less than twenty, and academic administrators can make it possible for large groups of faculty members to participate in a dialogue exercise through release time or other administrative adjustments.

\section{Conclusion}

If we view the world in terms of quantum theory, analyzing parts to understand the whole no longer makes sense. Bohm's work has shown us that there is an unbroken wholeness, a complex web of connections, at a level we cannot often discern (cited in Wheatley, 1993). Faculty developers need to find ways to create these connections for classroom instructors, to get teaching out of splendid isolation. Faculty development is moving out of its formative stage, in which we sought to add techniques and knowledge to a teacher's cognitive framework, to a transformative stage of examining assumptions and values that underlie teaching and the environment in which it operates. This movement is a complex process, a fact that Shulman acknowledges in his discussion of the intersection of content and pedagogy (Shulman, 1987). Faculty development must nevertheless 
continue to advance, to go beyond reflective practice to the exploitation of the dialogue technique. Only through these methods can faculty see beyond traditional paradigms of teaching and develop an understanding of collective meaning, a process that should yield a new level of creativity and insight into the practice of teaching.

In a quantum world it is through small connections that larger, more complex connections are affected. We know that changes in small settings, such as individual faculty groups, can create larger system changes that ultimately unite us in the whole. Thus, the quantum model of change matches our experience in the world and reflects organizational change with more accuracy than is usually acknowledged (Wheatley, 1993). On this basis, Wheatley reminds us to "think globally, and act locally" (1993, p. 42). If our commitment to faculty and students, and therefore society at large, is to create the best learning environment in which to conduct the business of education it is important that we explore ways to engage faculty members in "dialogue."

\section{References}

Bohm, D., Factor, D. \& Garrett, P. (1992). Dialogue: A proposal. Cambridge, MA: The Dialogue Project, Organizational Learning Center, Massachusetts Institute of Technology.

Brookfield, S. (1987). Developing critical thinkers: Challenging adults to explore alternative ways of thinking and acting. San Francisco: Jossey-Bass.

Cranton, P. (1994, November/;December). Self-directed and transformative instructional development. Journal of Higher Education, 6, 726-744

Cross, K.P., \& Angelo, T.A. (1988). Classroom assessment techniques. Ann Arbor, MI: National Center for Research to Improve Post-Secondary Teaching and Learning.

Daloz, L.A. (1987). Effective teaching and mentoring. San Francisco: Jossey-Bass.

Isaacs, W. (1992). Taking flight: Dialogue, collective thinking, and organizational learning. Cambridge, MA: Report from the Center for Organizational Learning, Massachusetts Institute of Technology.

. (1992). Dialogue project summary. Cambridge, MA: Report from the Center for Organizational Learning, Massachusetts Institute of Technology.

Katz, J. \& Henry, M. (1988). Turning professors into teachers: A new approach to faculty development and student learning. New York: MacMillian.

Mezirow, J. (1990). Transformative dimensions of adult learning. San Francisco: JosseyBass. 
Palmer, P. (1993, November/December). Good talk about good teaching: Improving teaching through conversation and community. Change, 6, 8-14.

Qualters, D. (1995, Winter). From practitioner to professor: A reflective vision. Journal of Staff,Program \& Organizational Development, 12, 1-6.

Schon, D. (1983). The reflective practitioner: How professionals think in action. New York: Basic Books.

Schein, E. (1993, Fall). On dialogue, culture, and organizational learning. Organizational Dynamics, 22, 40-51.

Sherman, T., Armistead, L., Fowler, F., Barksdale, M., \& Reif, G. (1987). The quest for excellence in university teaching. Journal of Higher Education, 58 (1), 66-84.

Schulman, L. (1993, November/December). Teaching as community property: Putting an end to pedagogical solitude. Change, 6, 6-7.

. (1987). Knowledge and teaching: Foundations of the new reform. Harvard Educational Review, 57 (1), 1-22.

Wheatley, M. (1993). Leadership and the new science: Learning about organization from an orderly universe. San Francisco: Berrett-Koehler.

Wlodkowski, R.J. (1985). Enhancing adult motivation to learn. San Francisco: JosseyBass. 